\title{
Sexual differentiation and reproductive development of female rat offspring after paternal exposure to the anti-tumor pharmaceutical cisplatin
}

\author{
Patrícia Villela e Silva ${ }^{a}$, Raquel Frenedoso da Silva ${ }^{a}$, Cibele dos Santos Borges ${ }^{a}$, \\ Marilia Martins Cavariani ${ }^{\mathrm{a}}$, Camila Contin Diniz de Almeida Francia ${ }^{\mathrm{b}}$, \\ Fernando Barbosa Júnior ${ }^{\mathrm{c}}$, Wilma De Grava Kempinas ${ }^{\mathrm{a}, *}$ \\ a Department of Morphology, Institute of Biosciences of Botucatu, UNESP-Univ Estadual Paulista, Botucatu, SP, Brazil \\ ${ }^{\mathrm{b}}$ Department of Anatomy, Institute of Biosciences of Botucatu, UNESP_Univ Estadual Paulista, Botucatu, SP, Brazil \\ ${ }^{c}$ Department of Clinical, Toxicological and Bromatological Analyses, Faculty of Pharmaceutical Sciences of Ribeirão Preto, USP-University of São Paulo, \\ Ribeirão Preto, SP, Brazil
}

\section{A R T I C L E I N F O}

\section{Article history:}

Received 23 February 2014

Received in revised form 2 December 2015

Accepted 5 February 2016

Available online 8 February 2016

\section{Keywords:}

Cisplatin

Female rat

Reproductive toxicity

Paternal exposure

\begin{abstract}
A B S T R A C T
Cisplatin (CP) is used to treat a number of cancers, including testicular cancer. Studies indicate that $\mathrm{CP}$-treatment can impair spermatogenesis in humans and rodents by germ cell DNA binding, through different modes of action. CP-paternal exposure resulted in adverse effects in F1 male offspring. In this study, F1 female offspring was assessed for reproductive development after CP-paternal exposure. Peripubertal male rats, treated with $1 \mathrm{mg} / \mathrm{Kg} /$ day of $\mathrm{CP}$ or vehicle for 3 weeks, were mated with unexposed females. $\mathrm{F} 1$ female offspring of $\mathrm{CP}$-treated fathers showed a decrease in fetal ovary germ cells, in estrous cycle length and FSH levels, and an increase in the percentage of antral follicles in adults. Based on our previous results and the findings of the present work we concluded that $\mathrm{CP}$-paternal exposure leads to adverse effects on rat male and female reproductive development, raising concern, in humans, for children born to men exposed to CP.
\end{abstract}

(c) 2016 Elsevier Inc. All rights reserved.

\section{Introduction}

Cancer is a leading cause of death worldwide. Cisplatin (CP) is a chemical complex with platinum widely used as an anti-tumor pharmaceutical in the treatment of ovarian, head and neck, bladder, colorectal, lung and testicular cancer [1-7]. Advances in multimodal treatment (surgery, chemotherapy and radiotherapy) have increased survival, particularly when performed soon after diagnosis [8].

Testicular cancer, specially germ cell tumors, is one of the most common types of cancer affecting young men, between 15 and 35 years old [9]. Despite the therapeutic success of CP in this type of cancer [6,7], it can cause several adverse effects, including nephrotoxicity, neurotoxicity, ototoxicity and abnormal spermatogenesis $[10,11]$.

\footnotetext{
* Corresponding author at: Laboratory of Reproductive and Developmental Biology and Toxicology, Department of Morphology, Institute of Biosciences of Botucatu, UNESP_-Univ Estadual Paulista, 18618-689 Botucatu, SP, Brazil.

E-mail address: kempinas@ibb.unesp.br (W. De Grava Kempinas).
}

The ability of CP to inhibit tumor growth is a result of several factors, including diffusion through the cell membrane, accumulation in the cells and the binding to tumor cell DNA, generating adducts [12]. The formation of covalent bonds with DNA affects fundamental cellular processes, inducing tumor cell apoptosis [13]. However, it can also bind to DNA of germ cells, resulting in azoospermia or oligospermia in men [14]. In rodents, the treatment with CP resulted in formation of CP-DNA adducts in the testis $[15,16]$.

Studies have shown that rodents with damaged DNA spermatozoa, such as CP-DNA adducts, can maintain their fertility capacity. However, there are evidences that, if not corrected by the repair system, these damages can be transmitted to the offspring, resulting in adverse effects in the progeny development $[17,18]$. These adverse effects may be resulted from alterations of genomic and epigenetic regulation during development, as observed in a study with cyclophosphamide, another chemotherapy agent that forms adduct with the spermatozoa DNA [19].

Another well-characterized mode of action for CP is the disruption of the redox balance of tissues leading to oxidative stress and reproductive toxicity [20-22]. The oxidative stress induced by $\mathrm{CP}$ mainly results from the combination of the drug with glutathione 
(GSH) tripeptide in the cytoplasm [23]. This interaction results in the formation of a complex that is converted into a highly reactive thiol compound into the cells. This compound can bind to essential proteins, leading to apoptosis [24-27]. Moreover, studies have reported that $\mathrm{CP}$ is capable of reducing the activities of antioxidant enzymes such as superoxide dismutase (SOD), catalase (CAT), glutathione peroxidase (GPx) [28], which contributes to the alteration of the oxidant-antioxidant balance and promotes oxidative stress. Adult male rats exposed to $7 \mathrm{mg} / \mathrm{Kg}$ of CP showed oxidative damage via induction of lipid peroxidation and reduction of the antioxidant defense system potency in testis, followed by a decrease in sperm concentration and motility as well as an increase in sperm abnormalities and testicular damage as evidenced by histopathology [20].

In a previous study from our laboratory, peri-pubertal male rats treated with $1 \mathrm{mg} / \mathrm{Kg} /$ day of CP for 3 weeks were evaluated as to reproductive parameters at post-puberty (PND 66) and adult age (PND 140, after a recovery period of 74 days) [29]. The post-pubertal male rats showed changes in reproductive parameters, such as decrease in sperm production and reserves, sperm with progressive movement, tubular diameter, intratesticular testosterone levels and fertility potential, as well as increased pre-implantation losses, number of TUNEL-positive seminiferous tubules and immotile sperm. Moreover, we observed changes in sexual behavior and testicular histology as seminiferous tubules with few layers of germ cells, vacuolization in Sertoli cells, acidophilic cells with pyknotic nuclei and flaking of immature germ cells. In the adulthood these changes were recovered, except for sperm motility and damage to testicular histology [29].

In another study, performed in the same experimental conditions, short and long-term reproductive effects of paternal exposure to $\mathrm{CP}$ were investigated in the male F1 generation. For this, the pre-pubertal treated rats were mated with unexposed females at the end of 3 weeks of CP exposure and at adulthood, i.e, 74 days after suspension of treatment. Impaired postnatal growth, delay in the age of testicular descent, decrease in seminal gland weight, delay in sperm transit through the epididymis and increase in sperm number in the caput/corpus epididymis were observed in the offspring obtained after mating the young males exposed to $\mathrm{CP}$. Testicular histopathological changes were also observed and persisted in the F1 generation of rats mated at adulthood. All the other parameters were comparable with the control group [17].

Given that, the present study aimed to investigate the reproductive development and fertility of the female offspring of young male rats, soon after the exposure to $\mathrm{CP}$.

\section{Materials and methods}

\subsection{Animals}

Male (45 days old, $\mathrm{n}=38$ ) and female (66 days old, $\mathrm{n}=38$ ) Wistar rats were supplied by the Central Biotherium of UNESP Univ Estadual Paulista and maintained in the Small Mammal Biotherium at the Department of Morphology, Institute of Biosciences, UNESP, Botucatu, SP, Brazil, under controlled conditions $\left(23 \pm 2{ }^{\circ} \mathrm{C}\right.$, $30 \%$ air humidity, 12:12-h photoperiod) with food and water delivered ad libitum. The animals were housed in polypropylene cages $(43 \mathrm{~cm} \times 30 \mathrm{~cm} \times 15 \mathrm{~cm})$ with laboratory-grade pine shavings as bedding. The experimental protocol followed the Ethical Principles in Animal Research of the Brazil College of Animal Experimentation and was approved by the Bioscience Institute/UNESP Ethics Committee for Animal Experimentation (protocol no 426CEUA).

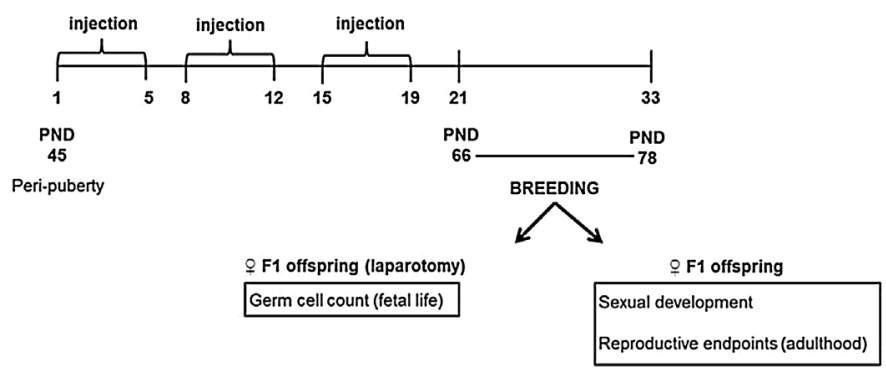

Fig. 1. Experimental design and treatment. $\mathrm{PND}=$ postnatal day.

\subsection{Experimental design and treatment}

The male rats were randomly divided into two experimental groups: control group $(n=20)$ that received $0.9 \%$ saline solution (vehicle) and the CP-treated group $(n=18)$ which received $1 \mathrm{mg} / \mathrm{Kg} /$ day of CP (cisdiammineplatinum (II) dichloride, Sigma Chemical Co., P4394, St. Louis, USA) diluted in vehicle, by intraperitoneal injection. Dose and treatment regimen were selected based on clinical use of the drug on human chemotherapy for testicular cancer [30]. The clinical dose of CP usually used in human $\left(20 \mathrm{mg} / \mathrm{m}^{2}\right)$ was converted to rat doses by adjusting for body weight/surface area ratio [31], and a third of the rat dose was selected based on our prior study [29]. The drug was administered 5 days per week, for 3 weeks, during peri-puberty, from postnatal day 45 (PND 45) until PND 63 (Fig. 1). Body weight was recorded throughout the experiment.

The study was conducted into two experiments. In experiment 1 , males from control $(n=10)$ and CP-treated $(n=8)$ groups were mated in separated cages with one naïve female per male for the evaluation of the F1 offspring fetal ovaries and blood platinum $(\mathrm{Pt})$ levels of male rats from experimental groups. In experiment 2 , another males ( $n=10 /$ group) treated with the same dose and time of exposure of the first experiment were mated in separated cages with another naïve females (one female per male) and were allowed to deliver the F1 offspring, whose postnatal female reproductive parameters were analyzed. In both experiments, pregnancy was detected by vaginal smears analysis after mating, and the presence of spermatozoa was considered day 0 of gestation (GD 0 ). The pregnant females were weighted each two days from GD 0 until GD 20.

\subsection{Experiment 1}

\subsubsection{Pt serum levels}

On PND 78, following the mating period, paternal rats from control $(n=10)$ or CP-treated $(n=8)$ groups were euthanized by $\mathrm{CO}_{2}$ inhalation followed by decapitation and the blood was collected from the ruptured cervical vessels into trace metals free tube containing $K_{2}$ EDTA anticoagulant (BD Vacutainer ${ }^{\circledR}$ ) for the determination of blood Pt levels, according to Brouwers et al.[32]. Measurement was performed using inductively coupled plasma-mass spectrometry (ICP-MS) (ELAN DRC II, Perkin Elmer, Norwalk, CT).

\subsubsection{Fetal ovaries}

Only 5 parental (P0) females, from the 8 originally mated, became pregnant and were euthanized in GD 20 by $\mathrm{CO}_{2}$ inhalation followed by decapitation and the ovaries from the fetuses $(n=5 /$ group) were collected. The gonads were fixed in Karnovsky (2.5\% glutaraldehyde, $8 \%$ paraformaldehyde), embedded in historesin, sectioned at $5 \mu \mathrm{m}$ and stained with hematoxylin and eosin. Germ cells were counted in 3 sections per animal with $50 \mu \mathrm{m}$ of 
Table 1

Litter size, sex ratio and absolute and relative anogenital distance of the F1 offspring from the control or CP-treated groups in PND 1.

\begin{tabular}{|c|c|c|}
\hline Parameters & Control & $\mathrm{CP}$ \\
\hline Mated females (n) & 10 & 10 \\
\hline Females that delivered viable litters (n) & 10 & 7 \\
\hline Number of pups ${ }^{\mathrm{a}}$ & $11.80 \pm 0.55$ & $11.57 \pm 0.81$ \\
\hline Female $^{\mathrm{a}}$ & $6.10 \pm 0.43$ & $5.57 \pm 0.43$ \\
\hline Male $^{\mathrm{a}}$ & $5.70 \pm 0.40$ & $6.00 \pm 0.69$ \\
\hline Sex ratio $(\%)^{a}$ & $108.30(80.36-146.70)$ & $100.00(85.71-120.00)$ \\
\hline \multicolumn{3}{|l|}{ Absolute anogenital distance (mm) } \\
\hline Female & $2.44 \pm 0.03(\mathrm{n}=58)$ & $2.37 \pm 0.04(\mathrm{n}=39)$ \\
\hline Male & $4.42 \pm 0.05(n=59)$ & $4.37 \pm 0.04(n=42)$ \\
\hline \multicolumn{3}{|l|}{ Relative anogenital distance $\left(\mathrm{mm} / \mathrm{g}^{1 / 3}\right)$} \\
\hline Female & $1.30 \pm 0.02$ & $1.29 \pm 0.02$ \\
\hline Male & $2.31 \pm 0.02$ & $2.34 \pm 0.02$ \\
\hline
\end{tabular}

a Sample size ( $\mathrm{n}$ ) expressed in litters. Values are expressed as mean \pm SEM (Student $t$-test), with exception for the sex ratio, expressed as median (Q1-Q3), Mann-Whitney test. $p>0.05$ for all comparisons.

Table 2

Mean body weight of the F1 male and female offspring from the control or CP-treated groups on postnatal days (PND) 1, 8, 13 and 22.

\begin{tabular}{|c|c|c|}
\hline Parameters & Control & $\mathrm{CP}$ \\
\hline \multicolumn{3}{|c|}{ Body weight on PND 1 (g) } \\
\hline Female & $6.63 \pm 0.06(n=57)$ & $6.21 \pm 0.08^{* * *}(\mathrm{n}=39)$ \\
\hline Male & $7.05 \pm 0.07(n=59)$ & $6.54 \pm 0.12^{* *}(n=42)$ \\
\hline Female and male & $6.85 \pm 0.05(n=117)$ & $6.38 \pm 0.08^{* * *}(\mathrm{n}=81)$ \\
\hline \multicolumn{3}{|c|}{ Body weight on PND 8 (g) } \\
\hline Female & $18.06 \pm 0.22(n=57)$ & $17.54 \pm 0.35(n=39)$ \\
\hline Male & $18.76 \pm 0.32(n=23)$ & $17.72 \pm 0.45(n=16)$ \\
\hline Female and male & $18.27 \pm 0.18(\mathrm{n}=80)$ & $17.59 \pm 0.28^{*}(n=55)$ \\
\hline \multicolumn{3}{|c|}{ Body weight on PND 13 (g) } \\
\hline Female & $27.13 \pm 0.38$ & $25.85 \pm 0.60$ \\
\hline Male & $27.94 \pm 0.58$ & $26.45 \pm 0.69^{*}$ \\
\hline Female and male & $27.36 \pm 0.32$ & $26.02 \pm 0.47^{* *}$ \\
\hline \multicolumn{3}{|c|}{ Body weight on PND 22 (g) } \\
\hline Female & $46.96 \pm 0.76$ & $48.09 \pm 0.99$ \\
\hline Male & $49.09 \pm 1.33$ & $48.57 \pm 0.85$ \\
\hline Female and male & $47.57 \pm 0.67$ & $48.23 \pm 0.74$ \\
\hline
\end{tabular}

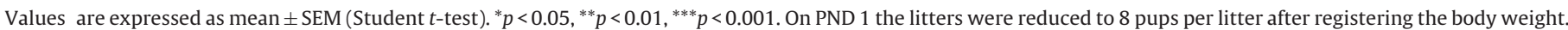

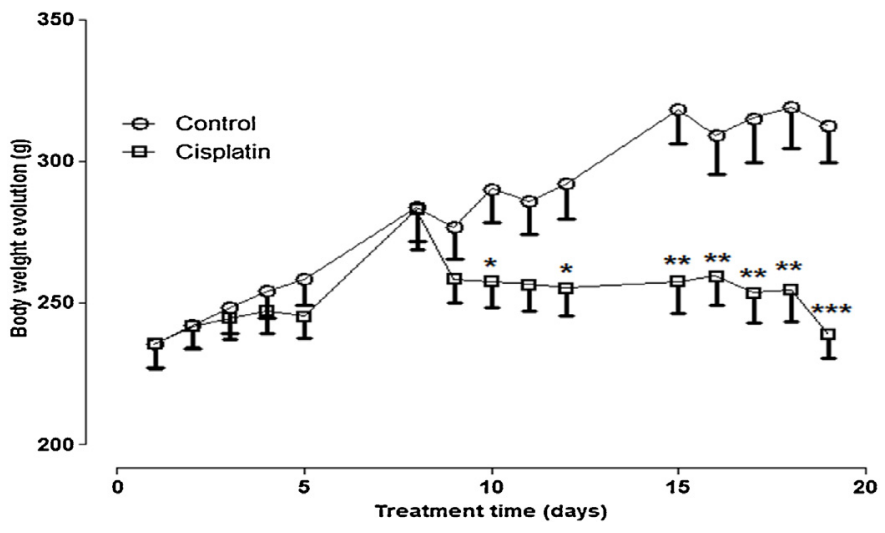

Fig. 2. Body weight gain ( $g$ ) of P0 male rats from control $(n=10)$ or CP-treated $(n=8)$ groups during treatment period. Values are expressed as mean \pm SEM. Student's t-test. ${ }^{*} p<0.05,{ }^{* *} p<0.01,{ }^{* * *} p<0.001$

distance among them and the results were expressed as germ cell number/area (germ cell number $/ \mathrm{mm}^{2}$ ).

\subsection{Experiment 2}

After the mating period, pregnant rats were weighed on alternate days from GD 0 until GD 20. The day of F1 pupsís delivery was recorded in the females mated with control or $\mathrm{CP}$-treated rats.

\subsubsection{Anogenital distance}

On PND 1 all the pups (male and female) were weighed and the anogenital distance (AGD, the distance from the anus to the genital papilla) measured with a Vernier caliper (Mitutoyo, 530-320, Japan). For this, the mother was allocated in a separated cage and each pup was gently held and the distance from the anus to the genital papilla was scored and normalized by dividing AGD to the cube root of body weight [33]. As AGD in males is approximately double that of females [34], all the pups were classified as male or female based on the AGD values. The sex ratio (number of female pups/number of male pups $\times 100$ ) and number of pups per litter (litter size) were scored and, afterwards, the offspring were equalized by reducing each litter to eight pups per mother, maintaining preferentially female pups. These pups were returned to the mother and the remaining pups were killed by decaptation.

On PND 22, the offspring were weaned, weighed and reduced to four females per litter. The male and female pups that were not used for the study were euthanized by $\mathrm{CO}_{2}$ inhalation followed by decapitation.

\subsubsection{Postnatal growth}

Both female and male pups from experimental groups that remained after the offspring size equalization were weighed in PND $1,8,13$ and 22 for the evaluation of body weight gain of the litters until weaning. 


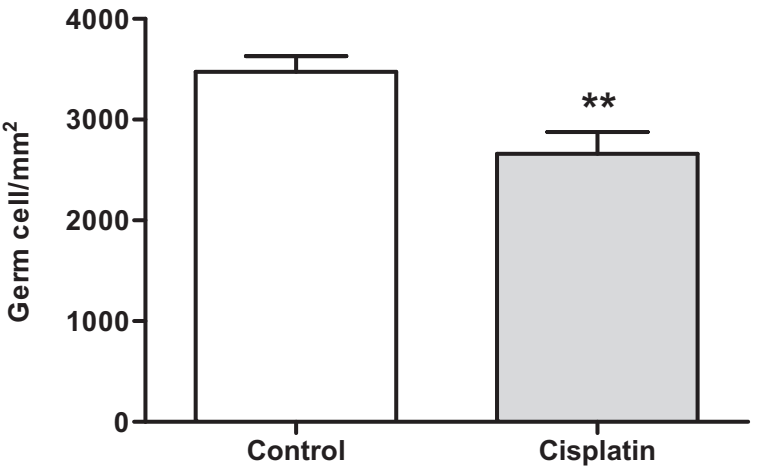

Fig. 3. Number of germ cells per ovarian area $\left(\mathrm{mm}^{2}\right)$ of $\mathrm{F} 1$ female fetuses from control $(n=5)$ or CP-treated $(n=5)$ groups. Values are expressed as mean $\pm S E M$. Student's $t$-test. ${ }^{* *} p<0.01$.

\subsubsection{Puberty onset}

From PND 30, four F1 females per litter were evaluated daily for the complete vaginal opening (VO), an external marker of puberty completion in rats [35].

\subsubsection{First estrus and estrous cyclicity}

After VO, the vaginal lavage was collected daily for the determination of the occurrence of the first estrus, characterized by the predominance of cornified squamous epithelial cells [36]. From PND 60 and over a period of 15 days, vaginal lavage of adult F1 female offspring from both control and CP-treated groups $(n=4$ females per litter) was collected for the assessment of the estrous cyclicity as described by Marcondes et al. [37] with some adaptations: each day at approximately the same time in the light cycle, $10 \mu \mathrm{L}$ of saline solution was gently introduced into the rat vagina with an automatic pipettor and the fluid aspired was placed on clean histological slides for analysis under a light microscope (10x magnification). The estrous cycle phases were classified based on the proportion of cellular types from the vaginal smear: proestrus (predominance of nucleated epithelial cells), estrus (predominance of anucleated cornified cells), metestrus (the same proportion among leukocytes, cornified, and nucleated epithelial cells) and diestrus (predominance of leukocytes). Data from each animal were used to calculate the frequencies of the phases (number of days in each phase), cycle length (number of days from the first day of a cycle phase to the first day of the next same phase) and number of cycles of the female F1 offspring from control and CP-treated groups.

\subsubsection{Collection of blood and organs}

During the first estrus after PDN 75, one female offspring per litter from females mated to control males $(n=10)$ or females mated to $\mathrm{CP}$-treated males $(\mathrm{n}=7)$, was weighed and euthanized by $\mathrm{CO}_{2}$ inhalation followed by decapitation. Blood was collected from the ruptured cervical vessels for the determination of sex hormonal levels as described below. Liver, kidney, pituitary, ovaries, uterus (with fluid) and adrenal glands were removed and their weight (absolute and relative to body weight) were recorded. The reproductive organs were fixed in Bouinís solution (75\% saturated picric acid solution, $25 \%$ formaldehyde and $5 \%$ acetic acid) for subsequent histological and immunohistochemical analysis.

\subsubsection{Histological analysis of reproductive organs}

After collected and fixed in Bouinís solution, ovary and right uterine horn from adult $F 1$ offspring ( $n=5$ /group) were processed and embedded in paraffin, sectioned at $5 \mu \mathrm{m}$, stained with hematoxylin and eosin. The ovaries were scanned for histomorphometric analysis with Panoramic Viewer software (3DHISTECH Ltd.) and the uterine horns were analyzed using a stereoscopic microscope (Leica MZ 125 Stereomicroscope) equipped with the Leica Application Suite Version 3.7.0 software.

The ovarian structures (corpora lutea and follicles) were counted in one section taken from the middle of the ovary per animal. Classification of the follicles was based on the different stages of follicular development, the morphology of the follicles and the number of layers of granulosa cells according to Borgeest et al. [38] and Talsness et al. [39]. Follicles were classified as primordial when the oocytes were surrounded by a single layer of squamous cells, while primary follicles were surrounded by a single layer of cuboidal epithelial cells. Preantral follicles were characterized by oocytes surrounded by more than one layer of granulose cells with no antral space. Antral follicles were classified when containing three or more layers of granulosa cells and a clearly defined antral space. Follicles were considered atretic if they presented pyknotic granulosa cells, disorganized granulosa cells, degenerating oocyte and detachment from the basement membrane. These follicles and corpora lutea are expressed as percentages of the total number of ovarian structures [40].

Three sections of the right uterine horns per animal were used to measure the following parameters: total uterine area $\left(\mu \mathrm{m}^{2}\right)$, myometrial, endometrial and luminal epithelium areas $\left(\mu \mathrm{m}^{2}\right)$, thickness and width index. The areas and perimeters of each region were measured by tracing around the images of the sections with a cursor, and the values were used to calculate the thickness, as described by Mosquete et al. [41], with adaptations. Endometrial and luminal epithelium width index were measured by deriving the width from their respective areas.

Heights of the luminal epithelium and endometrium $(\mu \mathrm{m})$ were measured in five different regions of three sections per animal.

\subsubsection{Immunohistochemistry}

After collected and fixed in Bouinís solution, the left uterine horns from adult $F 1$ offspring ( $n=5$ /group) were dehydrated in ethanol, embedded in paraplast and serial transverse sections $(5 \mu \mathrm{m})$ were mounted on silanized slides for immunohistochemical detection of the estrogen alpha receptor $(E R \alpha)$ and progesterone receptor (PR) proteins expression, using the polymer system (MACH 4 Universal HRP polymer Detection, Biocare, CA, USA) as described by Mariani et al. [42], with adaptation.

The slides were deparaffinized in xylene and rehydrated in decreased concentrations of ethanol followed by antigen recovery with citrate buffer $(0.01 \mathrm{M}, \mathrm{pH}$ 6.0) in a Pascal Pressure Chamber (DakoCytomation Denmark A/S) at $120^{\circ} \mathrm{C}$ for 5 min. Afterwards, the sections were allowed to cool down to room temperature, rinsed three times in phosphate-buffered saline (PBS), incubated in $3 \%$ of $\mathrm{H}_{2} \mathrm{O}_{2}$ diluted in PBS for 10 min to block endogenous peroxidase activity, rinsed again, incubated in $1 \%$ nonfat milk for $60 \mathrm{~min}$ and finally incubated overnight at $4{ }^{\circ} \mathrm{C}$ with mouse monoclonal anti-ER$\alpha$ (6F11, 1:50 dilution, Biocare Madical, USA) or rabbit polyclonal anti-PR (sc-538, 1:50 dilution, Santa Cruz Biotechnology, USA).

Following three $5 \mathrm{~min}$ washes at PBS and incubation at mouse and rabbit probe and HRP polymer for 10 min each at room temperature, the peroxidase activity was revealed using the 3,3'-diaminobenzidine tetrahydrochloride chromogen (DAB, Sigma-Aldrich Co., USA) for $10 \mathrm{~min}$ at room temperature. The slides were counterstained with Harris haematoxylin, dehydrated in ethanol, cleared with xylene and mounted with Permount.

The PR expression in the uterine luminal epithelium was qualitatively assessed, while ER $\alpha$ expression was semi-quantitatively assessed by manual scoring, based on the intensity of the DAB reaction product. The staining intensity was graded on a relative intensity scale of $(0)$ no visible staining, (1) low intensity of staining (medium brown) and (2) high intensity of staining (black or dark brown, apparently well localized and specific staining), adapted 
FSH
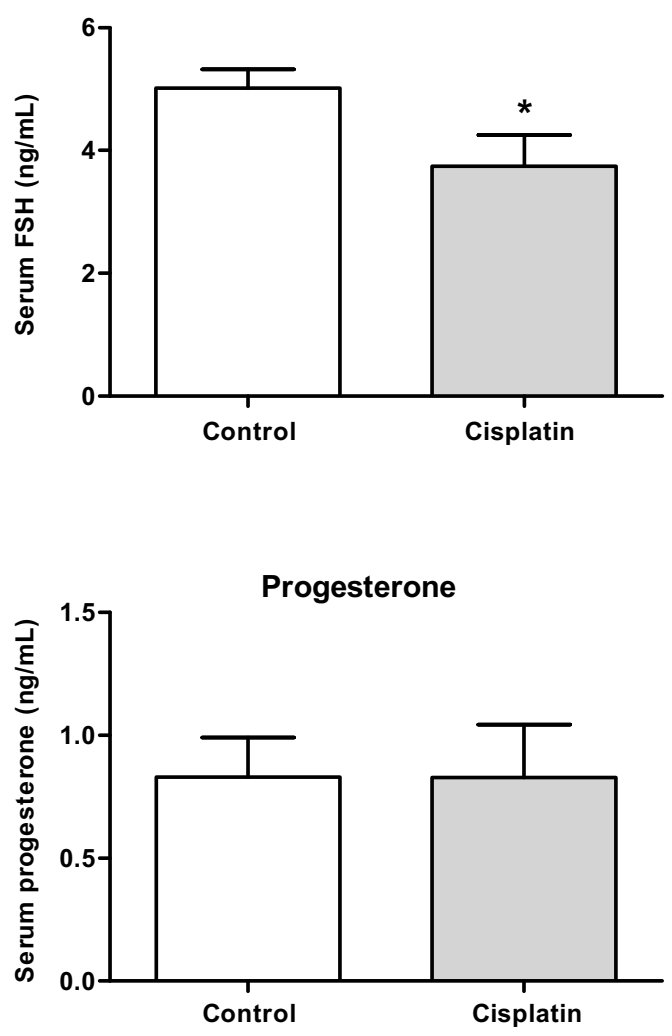

LH
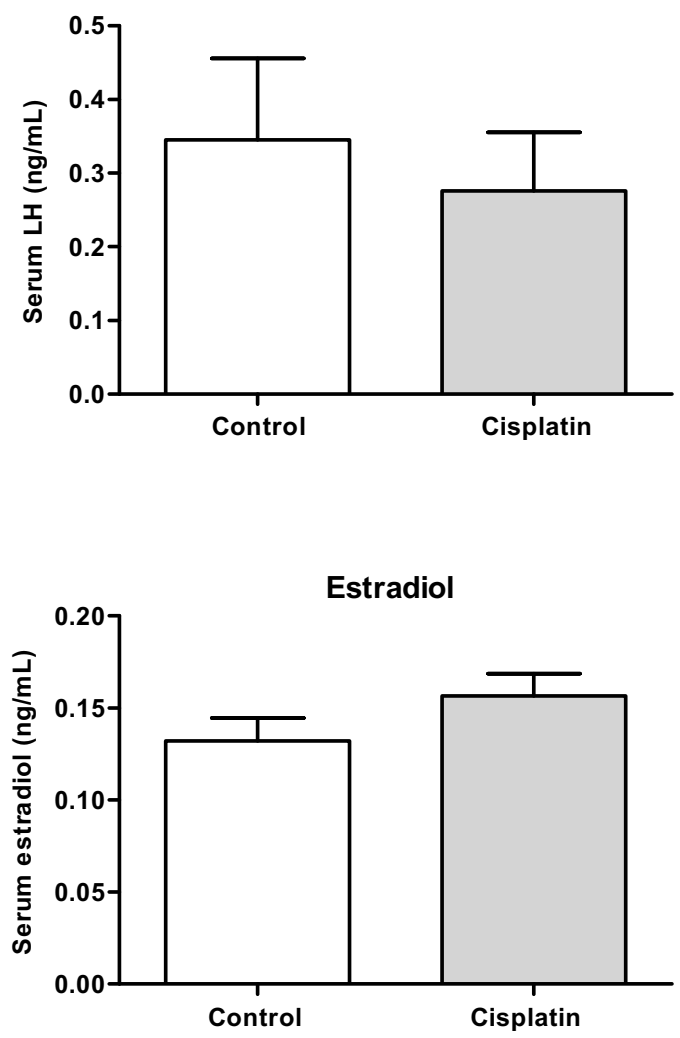

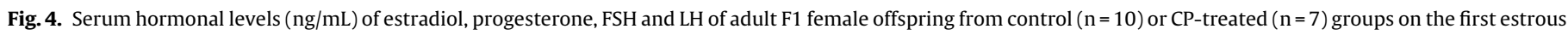
after PND 75. Values are expressed as mean \pm SEM. Student's $t$-test. ${ }^{*} p<0.05$.

from Petrusz et al. [43]. One transverse section of each sample was observed in the light microscope Leica DMLB and ten different areas (40x magnification) were selected in sequence to avoid overlapping localization. These areas were scanned in the image analyzer Leica Q-win software version 3.1 for Windows TM for cell counts, which was performed by a single rater.

To measure the percentage of stained cells that expressed ER $\alpha$ and PR, the number of cells from each intensity was divided by the total number of counted cells [44].

\subsubsection{Serum hormone levels}

The blood collected from the adult F1 females euthanized in the first estrus after PDN 75 was centrifuged at $4{ }^{\circ} \mathrm{C}$ for $20 \mathrm{~min}$ at $2400 \mathrm{rpm}$ and the serum collected was stored at $-20^{\circ} \mathrm{C}$ until analysis. Serum concentrations of estradiol, progesterone (PR), follicle-stimulating hormone (FSH) and luteinizing hormone ( $\mathrm{LH}$ ) were measured by using a double-antibody radioimmunoassay (RIA). Plasma FSH and LH concentrations were performed using specific kits supplied by the National Institute of Arthritis, Diabetes and Kidney Diseases (NIDDK, USA), while estradiol and progesterone concentrations were determined using MAIA kits provided by Biochem Immunosystems (Bologna, Italy). The intra-assay coefficient of variation was $3.4 \%$ for $\mathrm{LH}, 2.8 \%$ for $\mathrm{FSH}, 4.3 \%$ for estradiol and $7.5 \%$ for progesterone. All samples were dosed in duplicate and, when needed, at different dilutions. To avoid inter-assay variation, all samples of the same experiment were assayed in the same RIA.

\subsubsection{Sexual behavior}

Adult F1 female offspring from control $(n=10)$ or CP-treated groups ( $n=7$ ), one F1 female per litter, were assessed in the mating test. For this, after nine days of acclimation in the inverted dark cycle and during the first proestrus phase after PND 84, the females were introduced into the cage of a sexually mature male which were allowed to mount ten times on the female. During each mount, the presence or absence of lordosis was recorded and the results were expressed as lordosis quotient (LQ; number of lordosis/ten mounts $\times 100$ ), based on Guerra et al. [36].

\subsubsection{Fertility}

Immediately after the sexual behavior test, the same F1 females (one/litter) were evaluated for fertility. For this, they were maintained with the same male used in the behavior test for $4 \mathrm{~h}$ and, after that, vaginal smears were collected, examined and presence of spermatozoa was considered GD 0.

On GD 20, pregnant females were euthanized by $\mathrm{CO}_{2}$ inhalation followed by decapitation for the laparotomy procedure. The uterus and ovaries were collected and the number of corpora lutea, implantation sites (implants), early or late resorptions (depending on absence or presence of distinguishable features such as the head or limbs, respectively), live fetuses and fetal weights were recorded for subsequent determination of the following fertility parameters: pregnancy rate: number of pregnant females/number of inseminated females $\times 100$; implantation rate (efficiency of implantation): implantation sites/corpora lutea $\times 100$; pre-implantation loss rate: number of corpora lutea - number of implantations/number of corpora lutea $\times 100$; post-implantation loss rate: number of implantations - number of live fetuses/number of implantations $\times 100$; sex ratio: number of female fetuses/number of male fetuses $\times 100$ [45].

\subsection{Statistical analysis}

Data are presented as mean \pm standard error of mean (SEM) or median and interquartile range. Student's $t$-test was used for 


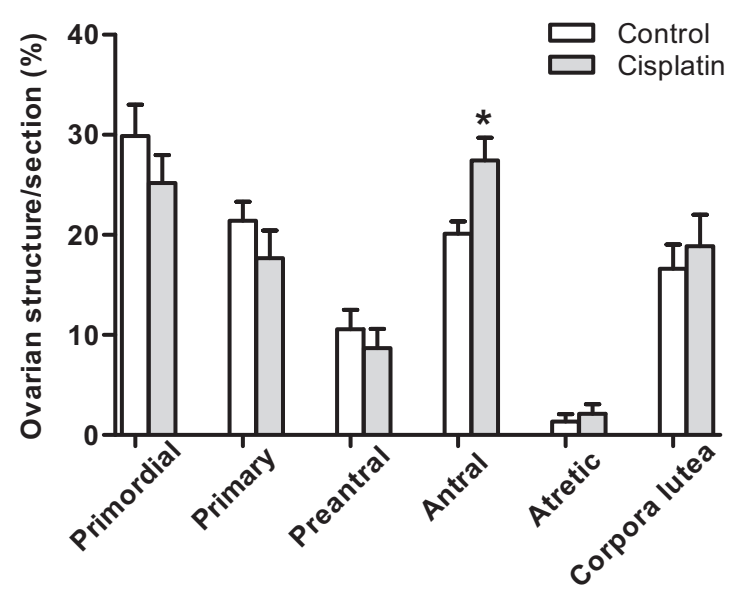

Fig. 5. Ovarian structures (follicles and corpora lutea) percentages from adult F1 female offspring of control $(n=7)$ or CP-treated $(n=7)$ groups. Values expressed as median (Q1-Q3). Mann-Whitney test. * $p<0.05$.

comparison of parametric variables. Nonparametric variables were compared by Mann-Whitney test. Chi-square test was utilized for comparison of the gestational rate between groups. Differences were considered significant when $p<0.05$. The statistical analyses were performed by GraphPad InStat (version 5).

\section{Results}

\subsection{Experiment 1}

\subsubsection{Effects in parental generation (PO)}

From day 10 until the end of treatment there was a significant reduction in the body weight gain of the male rats treated with $\mathrm{CP}$ (Fig. 2). The serum levels of Pt ( $\mu \mathrm{g} / \mathrm{L}$, mean \pm SEM, Mann-Whitney test) in males euthanized on PND 78 were significantly increased $(p<0.001)$ in CP-treated group $(2,411.00 \pm 146.50)$ when compared to control group $(0.30 \pm 0.25)$.

The gestational rate of the females mated to CP-treated males was significantly reduced (62.5\%, 5 pregnant in 8 inseminated rats) when compared to control group (100\%, $p<0.05$, Chi-square test).

\subsubsection{Fetal gonad analysis}

There was a significant decrease in the number of germ cells per ovarian area of female fetuses from females mated to CP-treated males when compared to the control males (Fig. 3). Heretofore, "treated offspring" are defined as "offspring from CP-treated males mated to untreated females" and "control offspring" are defined as "offspring from vehicle-treated males mated to untreated females".

\subsection{Experiment 2}

\subsubsection{Paternal analysis}

All sperm-positive females mated with males of the control group $(n=10)$ became pregnant, whereas in the treated group, the gestational rate was $80 \%$ ( 8 pregnant in 10 inseminated rats, $p>0.05$ ). These sperm-positive females from both groups delivered pups on GD 21 or GD 22, except one female from CP-treated group that gave birth to six stillborn fetuses on GD 23. In addition, this female presented 10 uterine resorption sites visualized by laparotomy.

During pregnancy, no statistical difference was observed in the body weight gain (GD 20 weight subtracted from the GD 0 weight) of the pregnant females mated with males from experimental groups ( $p>0.05$; data not shown).
Table 3

Age of complete vaginal opening (VO) and first estrus of the F1 female offspring from the control or CP-treated groups.

\begin{tabular}{lrr}
\hline Parameters & Control $(\mathrm{n}=40)$ & \multicolumn{1}{c}{$\mathrm{CP}(\mathrm{n}=28)$} \\
\hline VO (days) & $35.63 \pm 0.57$ & $35.04 \pm 0.53$ \\
Body weight on VO day $(\mathrm{g})$ & $114.00 \pm 2.89$ & $111.20 \pm 3.14$ \\
First estrus (days) & $37.40 \pm 0.71$ & $37.30 \pm 0.60$ \\
Body weight on first estrus day $(\mathrm{g})$ & $123.00 \pm 3.63$ & $123.70 \pm 3.17$ \\
\hline
\end{tabular}

Values are expressed as mean \pm SEM. Student $t$-test. $p>0.05$ for all comparisons.

Table 4

Assessment of estrous cycle regularity in the adult F1 female offspring from control or CP-treated groups.

\begin{tabular}{lll}
\hline Parameters & Control $(\mathrm{n}=40)$ & $\mathrm{CP}(\mathrm{n}=28)$ \\
\hline Frequency of proestrus (days) & $3.35 \pm 0.12$ & $2.96 \pm 0.13^{*}$ \\
Frequency of estrus (days) & $3.87 \pm 0.10$ & $3.54 \pm 0.16^{*}$ \\
Frequency of metestrus (days) & $4.60 \pm 0.30$ & $5.18 \pm 0.33$ \\
Frequency of diestrus (days) & $3.12 \pm 0.31$ & $3.25 \pm 0.37$ \\
Number of cycles & $2.82 \pm 0.06$ & $2.79 \pm 0.13$ \\
Estrous cycle length (days) & $4.21 \pm 0.07$ & $3.79 \pm 0.13^{* *}$ \\
\hline
\end{tabular}

Values are expressed as mean \pm SEM. Student $t$-test. ${ }^{* *} p<0.01$.

Table 5

Relative and absolute organ weights of adult F1 female offspring from control or CP-treated groups on the first estrus after PND 75.

\begin{tabular}{lcc}
\hline Parameters & Control $(\mathrm{n}=10)$ & $\mathrm{CP}(\mathrm{n}=7)$ \\
\hline Body weight $(\mathrm{g})$ & $225.20 \pm 6.98$ & $215.10 \pm 12.19$ \\
$\quad$ Absolute weights & $407.80 \pm 18.54$ & $363.50 \pm 25.26$ \\
Uterus $(\mathrm{mg})$ & $88.06 \pm 5.01$ & $86.10 \pm 5.99$ \\
Ovaries $(\mathrm{mg})$ & $12.65 \pm 1.61$ & $9.31 \pm 0.87$ \\
Pituitary $(\mathrm{mg})$ & $10.30 \pm 0.16$ & $9.49 \pm 0.56$ \\
Liver $(\mathrm{g})$ & $1.73 \pm 0.03$ & $1.63 \pm 0.09$ \\
Kidneys $(\mathrm{g})$ & $7.50 \pm 0.29$ & $8.43 \pm 0.74$ \\
Adrenal glands $(\mathrm{mg})$ & & \\
$\quad$ Relative weights & $182.20 \pm 8.68$ & $168.50 \pm 5.20$ \\
Uterus $(\mathrm{mg} / 100 \mathrm{~g})$ & $39.63 \pm 3.07$ & $40.00 \pm 1.40$ \\
Ovaries $(\mathrm{mg} / 100 \mathrm{~g})$ & $5.60 \pm 0.61$ & $4.30 \pm 0.26$ \\
Pituitary $(\mathrm{mg} / 100 \mathrm{~g})$ & $4.59 \pm 0.13$ & $0.73 \pm 0.16$ \\
Liver $(\mathrm{g} / 100 \mathrm{~g})$ & $0.77 \pm 0.25$ & $3.91 \pm 0.26$ \\
Kidneys $(\mathrm{g} / 100 \mathrm{~g})$ & $3.35 \pm 0.13$ & \\
Adrenal glands $(\mathrm{mg} / 100 \mathrm{~g})$ &
\end{tabular}

Values are expressed as mean \pm SEM. Student $t$-test. $p>0.05$.

\subsubsection{Reproductive analysis of the adult female offspring}

The absolute and relative AGD of the offspring, as well as the litter size and sex ratio were similar between experimental groups $(p>0.05$; Table 1$)$. On PND 1,8 and 13 , there was a statistically significant decrease in the mean body weight of the litters (females and males) from CP-treated rats $(p<0.0001, p=0.0382$ and $p=0.0095$, respectively) (Table 2 ). The mean body weights of the male and female pups were significantly reduced on PND 1 $(p<0.0001$ and $p=0.001$, respectively). On PND 13, only the male pups showed significant decrease in body weight $(p=0.0385)$.

Evaluation of the age of $\mathrm{VO}$ and first estrus showed that paternal treatment with CP did not interfere with these parameters ( $p>0.05$; Table 3 ). However, there was a statistically significant decrease in the estrus cycle length and in the frequencies of proestrus and estrus in the offspring of CP-treated group (Table 4).

The absolute and relative organ weights of the female offspring euthanized on the first estrus after PDN 75 were similar between groups ( $p>0.05$; Table 5 ). In contrast, assessment of the hormonal levels revealed that FSH serum concentrations were significantly reduced in $\mathrm{CP}$-treated group, but not on estradiol, $\mathrm{LH}$ or progesterone (Fig. 4).

Histological analysis of the ovary and uterus of the adult female offspring showed no evidence of structural alterations after $\mathrm{CP}$ paternal treatment. There were also no intergroup differences in 
Table 6

Area $\left(\mu \mathrm{m}^{2}\right)$, thickness and width index and height $(\mu \mathrm{m})$ of different uterine regions in adult F1 female offspring from control $(n=5)$ or CP-treated $(n=5)$ groups.

\begin{tabular}{lcc}
\hline Parameters & Control $(\mathrm{n}=5)$ & $\mathrm{CP}(\mathrm{n}=5)$ \\
\hline Area $\times 10^{-4}\left(\mu \mathrm{m}^{2}\right)$ & & \\
$\quad$ Uterus & $679.20 \pm 31.74$ & $756.1 \pm 42.57$ \\
$\quad$ Endometrium & $304.70 \pm 19.53$ & $323.70 \pm 20.16$ \\
$\quad$ Myometrium & $26.26 \pm 1.67$ & $199.20 \pm 12.07$ \\
$\quad$ Luminal epithelium & & $25.95 \pm 4.23$ \\
Thickness index & $329.80 \pm 11.36$ & \\
$\quad$ Endometrium & $194.40 \pm 7.45$ & $340.20 \pm 19.43$ \\
$\quad$ Myometrium & $28.33 \pm 1.11$ & $209.80 \pm 13.05$ \\
Luminal epithelium & & \\
Width index $\left(\times 10^{3}\right)$ & $0.70 \pm 0.04$ & $0.63 \pm 0.01$ \\
$\quad$ Endometrium & $2.63 \pm 0.23$ & $2.36 \pm 0.11$ \\
Luminal epithelium & & \\
Height $(\mu \mathrm{m})$ & $724.50 \pm 59.66$ & $35.85 \pm 14.08$ \\
$\quad$ Endometrium & $38.00 \pm 1.30$ & \\
Luminal epithelium & & \\
\hline
\end{tabular}

Mann-Whitney test. Values expressed as mean \pm SEM. $p>0.05$ for all comparisons.

Table 7

Percentages of luminal epithelial cells immunostained for ER $\alpha$ in adult F1 female offspring from control $(n=5)$ or CP-treated $(n=5)$ groups.

\begin{tabular}{lll}
\hline Staining intensity & Control $(\mathrm{n}=5)$ & $\mathrm{CP}(\mathrm{n}=5)$ \\
\hline $0(\%)$ & $8.56(6.53-12.56)$ & $10.44(9.02-12.83)$ \\
$1(\%)$ & $29.47(23.48-34.97)$ & $44.21(19.02-52.76)$ \\
$2(\%)$ & $61.96(57.21-65.25)$ & $46.05(36.86-69.16)$ \\
\hline
\end{tabular}

Values expressed as median (Q1-Q3). Mann-Whitney test. $p>0.05$.

the results of uterine histomorphometry $(p>0.05$; Table 6$)$. On the other hand, assessment of the ovarian structures (follicles and corpora lutea) showed a statistically significant increase in the percentage of antral follicles (Fig. 5) in the CP-treated group.

Immunohistochemical analysis of the right uterine horns revealed no statistically significant difference in the ER $\alpha$ and PR proteins expression pattern on the luminal epithelium in $\mathrm{CP}$ treated group when compared to the control group (Figs. 6 and 7). Semi-quantitative analysis of the ER $\alpha$ expression showed no statistical difference between groups ( $p>0.05$; Table 7$)$.

In the first proestrus after PND 84, no statistical difference between the female offspring treated $v s$. control groups was observed in sexual behavior test, calculated by lordosis quotient (data not shown). Fertility measures were not statistically significant in female offspring from CP-treated fathers compared to controls ( $p>0.05$; Table 8).

\section{Discussion}

Cisplatin is a pharmaceutical widely used in the treatment of several cancers, including germ cell tumor [6,7], affecting men aged 15-35 years old. The most commonly used $\mathrm{CP}$ doses are between $20 \mathrm{mg} / \mathrm{m}^{2}$ or $40 \mathrm{mg} / \mathrm{m}^{2}$ daily, administered five consecutive days a week, for 2-5 weeks, by intravenous injection [30,46-48]. Despite its high activity and wide use, studies in human and rats have demonstrated that the therapeutical success can be accompanied by side effects, including nephrotoxicity, neurotoxicity, ototoxicity, and abnormal spermatogenesis $[10,11,49]$. In rats, a single intraperitoneal injection of $7 \mathrm{mg} / \mathrm{kg}$ of CP resulted in oxidative damages and reduction in the antioxidant defense system in the testis tissue, leading to reproductive toxicity [50].

It is known that the main mechanism of action of $\mathrm{CP}$ to inhibit tumor cells growth is through the formation of platinumDNA adducts, leading to apoptosis in germ cells, azoospermia or oligospermia in men [14,51]. In rodents, treatment with a single dose of $6 \mathrm{mg} / \mathrm{kg}$ of CP resulted in DNA adduct formation in the testis,
Table 8

Parameters of sexual behavior and fertility of adult F1 female offspring of control or CP-treated groups.

\begin{tabular}{|c|c|c|}
\hline Parameters & Control $(n=10)$ & $\mathrm{CP}(\mathrm{n}=7)$ \\
\hline Lordosis coefficient $^{\mathrm{a}}$ & $100.00(90.00-100.00)$ & $100.00(10.00-100.00)$ \\
\hline Gestational rate $(\%)^{\mathrm{b}}$ & 100 & 100 \\
\hline Implantation rate (\%) & $94.44(93.33-100.00)$ & $92.86(84.62-100.00)$ \\
\hline Fetal weight $(\mathrm{g})^{\mathrm{c}}$ & $3.40 \pm 0.06$ & $3.60 \pm 0.14$ \\
\hline Placenta weight $(\mathrm{g})^{\mathrm{c}}$ & $0.53 \pm 0.15$ & $0.51 \pm 0.01$ \\
\hline Number of live fetuses ${ }^{c}$ & $13.60 \pm 0.43$ & $11.14 \pm 1.37$ \\
\hline Number of corpora lutea ${ }^{c}$ & $15.20 \pm 0.61$ & $14.57 \pm 0.78$ \\
\hline Number of implantations ${ }^{c}$ & $14.50 \pm 0.48$ & $12.86 \pm 0.70$ \\
\hline Number of resorptions ${ }^{c}$ & $0.90 \pm 0.35$ & $1.86 \pm 0.86$ \\
\hline Sex ratio $(\%)^{\mathrm{a}}$ & $116.70(49.17-170.00)$ & $114.30(55.56-225.00)$ \\
\hline Pre-implantation loss (\%) & $5.56(0.00-6.67)$ & $7.14(0.00-15.38)$ \\
\hline Post-implantation loss (\%) & $3.33(0.00-13.57)$ & $9.09(0.00-27.27)$ \\
\hline
\end{tabular}

Sample size ( $\mathrm{n}$ ) expressed in litters. ${ }^{\mathrm{a}}$ Values expressed as median (Q1-Q3). ${ }^{\mathrm{b}} \mathrm{Chi}$ square test. ${ }^{C}$ Mann-Whitney test. ${ }^{3}$ Values expressed as mean \pm SEM. Student $t$-test. $p>0.05$ for all comparisons.

which was detected in the nuclei by immunohistochemistry for up to 9 days following treatment [16]. In another study with rats, in which the formation of DNA adducts was quantified by ELISA in the testis following the treatment with a single intraperitoneal dose of $8 \mathrm{mg} / \mathrm{kg}$ of CP, $40-50 \%$ of the adducts present at day 2 persisted until days 7 and 14 [15]. Atessahin et al. [52] reported that administration of a single dose of $7 \mathrm{mg} / \mathrm{kg}$ of CP in mice resulted in significant reduction of spermatozoa concentration and motility as well as the increased rates of sperm abnormalities.

Currently, there are several studies in the literature demonstrating direct effects of $\mathrm{CP}$ exposure on male and female genital systems [53-55]. However, few of them have reported the effects of paternal exposure to the drug on the reproductive system and fertility of the offspring. In a previous work [17] we demonstrated, in the male offspring of male rats exposed to CP at peri-puberty, delay in postnatal growth and testicular descent, decrease in seminal gland weight and adverse effects in the spermatogenesis. In the present study, carried out to evaluate the female offspring of male rats exposed to $\mathrm{CP}$ in the same experimental conditions, reproductive dysfunctions were also observed. Although DNA integrity was not evaluated, we observed a significant increase in Pt levels in blood that may have resulted in spermatozoa DNA-adduct formation and increased germ cell apoptosis.

In Experiments 1 and 2, the gestational rates were reduced in the females mated with the treated males, compared with the control group, corroborating results from a previous study [29]. Increase in pre- and post-implantation losses were reported by Seethalakshmi et al. [56] in male rats exposed to $0.5 \mathrm{mg} / \mathrm{Kg}$ of CP for 9 weeks.

In the present work one female from CP-treated group delivered stillborn pups on GD 23 and the remaining litter were resorbed. Delivery delay and litter mortality were also observed in previous works in females mated to CP-exposed males [17,53]. Further studies should be performed to elucidate this indirect effect of paternal exposure to $\mathrm{CP}$.

Interestingly, in the present work the litter size as well as the absolute and relative anogenital distances of male and female F1 offspring at PND 1 were comparable between groups. However, the postnatal growth of offspring was affected by paternal exposure to $\mathrm{CP}$, as observed by a significant decrease in the mean body weight of the litters.

Puberty in mammals is timed by the increase in gonadotropinreleasing-hormone (GnRH) secretion [57], which promotes gonadal steroidogenesis. In rats, the age of vaginal opening and first estrus are markers of age of puberty onset in females [35]. The estrous cycle in these animals begins immediately after the vaginal opening, which occurs around PND 32 and PND 36 [58]. In the present study, no changes were observed in the age of vaginal opening and 

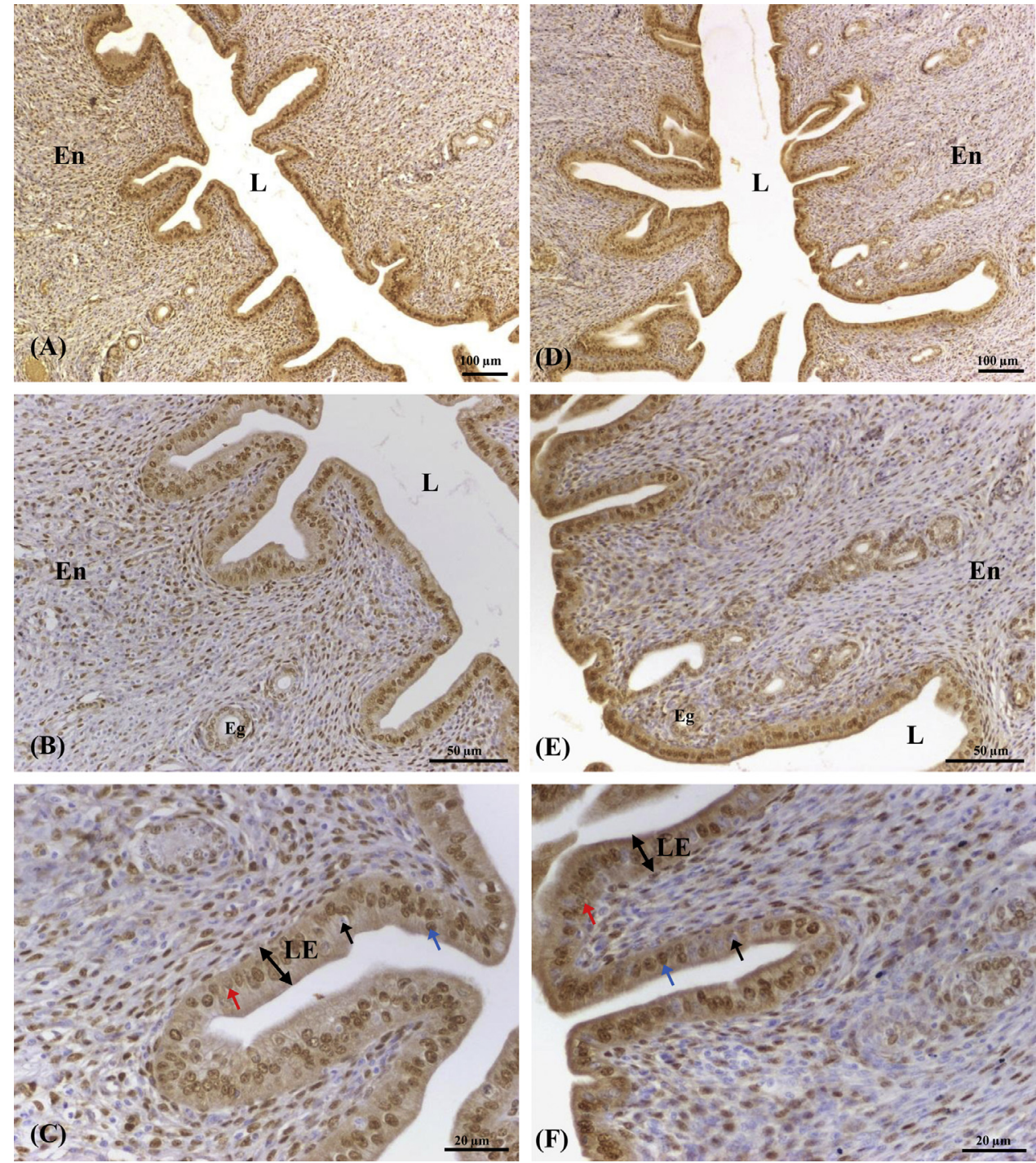

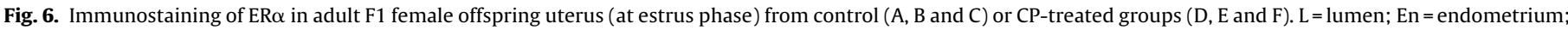

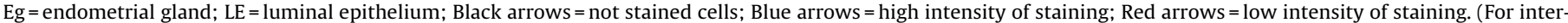
pretation of the references to colour in this figure legend, the reader is referred to the web version of this article.)

first estrus of F1 female offspring, indicating that puberty onset was not affected by paternal exposure to CP. FSH is a hormone that stimulates follicular development in post-pubertal mammals and represents an important indicative of follicular reserve in the ovaries. However, it is only in the last stages of maturation that follicles are under control of this hormone [59]. The secretion of FSH, in turn, is regulated by the levels of estradiol, which is synthesized by the granulosa cells of the follicles [59]. In the present study, adult F1 female offspring of CP-treated group showed a significant decrease in the serum concentration of FSH. Despite the fact that no gross structural damage was found in the ovaries and uterus of the female offspring, the histomorphometric assessment of the ovarian structures in adult female offspring revealed a significant increase of antral follicles in CP-treated group. There were no significant intergroup differences in circulating estrogen levels, but emerging evidence suggests that local production of estradiol is an important factor in the regulation of the differentiation and function of granulosa cells of developing follicles. Uterine receptors for estrogen and progesterone were not altered by paternal CP treatment, as revealed by immunohistochemistry.

In the present study, the length of the estrous cycles and the frequencies of estrus and proestrus phases were significantly reduced in the adult F1 offspring of $\mathrm{CP}$-treated group when compared to control group. Although we do not have an explanation for this result, based on the endpoints herein evaluated, we hypothesize a dysregulation in the estrous cyclicity in the offspring of $\mathrm{CP}$-exposed males.

No significant changes were detected in the weights of vital and reproductive organs in female progeny from $\mathrm{CP}$-treated fathers consistent with most of the findings of Favareto et al. [17]. In addition, there were no significant differences in sexual behavior and fertility in the female offspring after paternal CP treatment. However, the number of litters evaluated in the present study may have limited the findings of adverse effects in the F1 female offspring.

In female mammals, the reproductive lifespan is determined by the pool of primordial follicles established during embryonic development, which is essential for reproductive success since represents the total population of available germ cells during their entire reproductive life $[60,61]$. The analysis of fetal ovaries revealed a decrease in the number of germ cells per ovarian area in the F1 offspring of CP-treated group when compared to control group. However, in the adult females the ovarian structures were not affected by paternal $\mathrm{CP}$, with an exception for the increased incidence of antral follicles. Adler and Tarras [62] reported that 

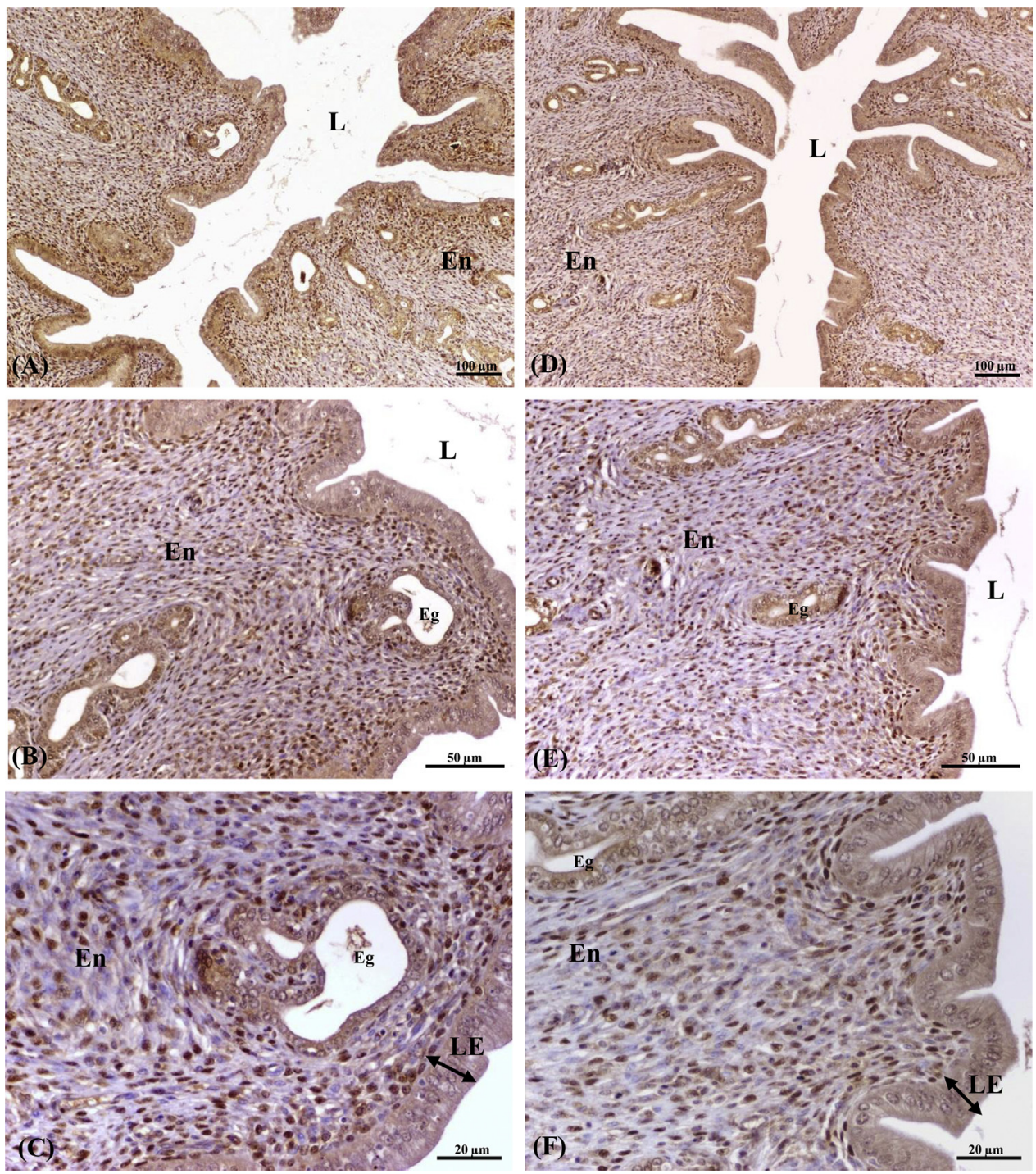

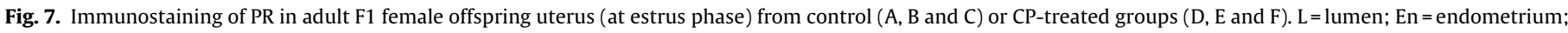
$\mathrm{Eg}=$ endometrial gland; $\mathrm{LE}=$ luminal epithelium.

the exposure of mice to $\mathrm{CP}$ resulted in aberrations in germ cells during the premeiotic phase of DNA synthesis. It is becoming established that sperm DNA damage can result in adverse effects in the offspring [18]. Thus, in the present study, although sperm DNA damage was not investigated, we postulate that these results were mediated by epigenetic mechanisms [19,63]. However, one limitation of our study is that only one ovary section was analyzed per animal.

Studies show that alterations in sperm methylation patterns are associated with infertility and transgenerational effects in human and rodents [64-66]. Chan et al. [67] reported that rats treated for 9 weeks with bleomycin-etoposide-cisplatin (BEP), a cocktail used for testicular cancer, showed epigenetic alterations of methylation patterns in spermatozoa DNA. In addition, studies in resistant tumor cells to CP treatment showed that the formation of DNAplatinum adducts is accompanied by the activation of cellular self-defense system by activating or silencing a variety of different genes that are required for cytotoxicity, leading to epigenetic and/or genetic alterations $[68,69]$. In the present study, the male rats treated with $\mathrm{CP}$ maintained their reproductive capacity to sire the offspring. Thus, based on aforementioned studies and given the findings on female offspring in the present study, and the findings on male offspring from our previous study [17], we suggest that possible alterations in spermatozoa DNA methylation patterns may be involved in the reproductive developmental effects observed in the offspring after paternal exposure to $\mathrm{CP}$.

Although we cannot rule out the mechanisms responsible for the effects observed in the present study, and due to the relatively small number of litters assessed, our study is pioneer showing morphofunctional adverse effects in the female offspring of young male rats exposed to $\mathrm{CP}$. Moreover, the results of the present work in conjunction with a previous work revealed that the male offspring may be more vulnerable to reproductive toxicity than the female offspring after paternal exposure to $\mathrm{CP}$.

In summary, our results in rats raise concern for the children born to human males being treated with $\mathrm{CP}$. Future research needs include analysis of DNA integrity of the sperm of CP-treated males, spermatozoa DNA methylation patterns, multi-dose studies, and shorter dose intervals to determine the critical window of male exposure in order to minimize the adverse effects of paternal exposure to $\mathrm{CP}$ on the offspring.

\section{Conflict of interest}

The authors declare that there are no conflicts of interest. 


\section{Transparency document}

The Transparency document associated with this article can be found in the online version.

\section{Acknowledgements}

This work was supported by The São Paulo Research Foundation (FAPESP, Grant 2012/12970-1), Coordinating Body for the Improvement of Postgraduate Studies in Higher Education (CAPES) and National Council for Scientific and Technological Development (CNPq, Grant 308842/2013-8). The authors are grateful to José Eduardo Bozano for technical support, Dr. Janete Aparecida Anselmo-Franci and Dr. Ruither de Oliveira Gomes Carolino of the Department of Morphology, Stomatology and Physiology, Dental School of Ribeirão Preto, USP for the hormonal assays, Carlos César Ramos of the Department of Pathology, Botucatu Medicine School, UNESP for the scanning of histological slides and Dr. Luis Fernando Barbisan and Guilherme Ribeiro Romualdo of the Department of Morphology, Institute of Biosciences of Botucatu, UNESP for the help in performing the immunohistochemical analyzes.

\section{References}

[1] M. Ikeda, K. Matsumoto, Y. Niibe, T. Satoh, T. Fujita, M. Iwamura, et al., The radiotherapy with methotrexate, vinblastine, doxorubicin, and cisplatin treatment is an effective therapeutic option in patients with advanced or metastatic bladder cancer, J. Radiat. Res. (Tokyo) 52 (2011) 674-679.

[2] J.Y. Park, K.L. Jin, D.Y. Kim, J.H. Kim, Y.M. Kim, K.R. Kim, et al., Surgical staging and adjuvant chemotherapy in the management of patients with adult granulosa cell tumors of the ovary, Gynecol. Oncol. 125 (2012) 80-86.

[3] J. Gilbert, M.A. Rudek, M.J. Higgins, M. Zhao, S. Bienvenu, N. Tsottles, et al., A phase I trial of erlotinib and concurrent chemoradiotherapy for stage III and IV (M0) squamous cell carcinoma of the head and neck, Clin. Cancer Res. 18 (2012) 1735-1742.

[4] K. Takara, M. Fujita, T. Minegaki, K. Yamamoto, M. Takahashi, T. Yokoyama, et al., Treatment schedule-dependent effect of 5-fluorouracil and platinum derivatives in colorectal cancer cells, Eur. J. Pharm. Sci. 45 (2012) 272-281.

[5] S.R. Gameiro, J.A. Caballero, J.W. Hodge, Defining the molecular signature of chemotherapy-mediated lung tumor phenotype modulation and increased susceptibility to T-cell killing, Cancer Biother Radiopharm. 27 (2012) 23-35.

[6] L.H. Einhorn, Treatment of testicular cancer: a new and improved model, J. Clin. Oncol. 8 (1990) 1777-1781.

[7] L.H. Einhorn, R.S. Foster, Bleomycin, etoposide, and cisplatin for three cycles compared with etoposide and cisplatin for four cycles in good-risk germ cell tumors: is there a preferred regimen? J. Clin. Oncol. 24 (2006) 2597-2598, author reply 8-9.

[8] A. Rosen, G. Jayram, M. Drazer, S.E. Eggener, Global trends in testicular cancer incidence and mortality, Eur. Urol. 60 (2011) 374-379.

[9] R. Segal, Surveillance programs for stage I nonseminomatous germ cell tumors of the testis, Urol. Oncol. 24 (2006) 68-74.

[10] P. Sawhney, C.J. Giammona, M.L. Meistrich, J.H. Richburg, Cisplatin-induced long-term failure of spermatogenesis in adult C57/Bl/6J mice, J. Androl. 26 (2005) 136-145.

[11] T. Erdem, T. Bayindir, A. Filiz, M. Iraz, E. Selimoglu, The effect of resveratrol on the prevention of cisplatin ototoxicity, Eur. Arch. Otorhinolaryngol. 269 (2012) 2185-2188.

[12] E. Gabano, D. Colangelo, A.R. Ghezzi, D. Osella, The influence of temperature on antiproliferative effects, cellular uptake and DNA platination of the clinically employed Pt(II)-drugs, J. Inorg. Biochem. 102 (2008) 629-635.

[13] E.R. Jamieson, S.J. Lippard, Structure, recognition, and processing of cisplatin-DNA adducts, Chem. Rev. 99 (1999) 2467-2498.

[14] S.G. Lutzker, N.J. Barnard, Testicular germ cell tumors: molecular understanding and clinical implications, Mol. Med. Today 4 (1998) 404-411.

[15] M.C. Poirier, E. Reed, C.L. Litterst, D. Katz, S. Gupta-Burt, Persistence of platinum-ammine-DNA adducts in gonads and kidneys of rats and multiple tissues from cancer patients, Cancer Res. 52 (1992) 149-153.

[16] P.M. Terheggen, B.G. Floot, E. Scherer, A.C. Begg, A.M. Fichtinger-Schepman, L. den Engelse, Immunocytochemical detection of interaction products of cis-diamminedichloroplatinum(II) and

cis-diammine(1,1-cyclobutanedicarboxylato) platinum(II) with DNA in rodent tissue sections, Cancer Res. 47 (1987) 6719-6725.

[17] A.P. Favareto, F.C. de Toledo, G. Kempinas Wde, Paternal treatment with cisplatin impairs reproduction of adult male offspring in rats, Reprod. Toxicol. 32 (2011) 425-433.

[18] S.B. Hooser, W.C. van Dijk-Knijnenburg, I.D. Waalkens-Berendsen, A.E. Smits-van Prooije, N.J. Snoeij, R.A. Baan, et al., Cisplatin-DNA adduct formation in rat spermatozoa and its effect on fetal development, Cancer Lett. 151 (2000) 71-80.

[19] W. Harrouk, S. Khatabaksh, B. Robaire, B.F. Hales, Paternal exposure to cyclophosphamide dysregulates the gene activation program in rat preimplantation embryos, Mol. Reprod. Dev. 57 (2000) 214-223.

[20] O. Ciftci, A. Cetin, M. Aydin, K. Kaya, F. Oguz, Fish oil, contained in eicosapentaenoic acid and docosahexaenoic acid, attenuates testicular and spermatological damage induced by cisplatin in rats, Andrologia (2013).

[21] C.R. Silva, L.M. Antunes, M.L. Bianchi, Antioxidant action of bixin against cisplatin-induced chromosome aberrations and lipid peroxidation in rats, Pharmacol. Res. 43 (2001) 561-566.

[22] Y.O. Ilbey, E. Ozbek, M. Cekmen, A. Simsek, A. Otunctemur, A. Somay, Protective effect of curcumin in cisplatin-induced oxidative injury in rat testis: mitogen-activated protein kinase and nuclear factor-kappa B signaling pathways, Hum. Reprod. 24 (2009) 1717-1725.

[23] M.H. Hanigan, P. Devarajan, Cisplatin nephrotoxicity: molecular mechanisms, Cancer Ther. 1 (2003) 47-61.

[24] M.H. Hanigan, E.D. Lykissa, D.M. Townsend, C.N. Ou, R. Barrios, M.W. Lieberman, Gamma-glutamyl transpeptidase-deficient mice are resistant to the nephrotoxic effects of cisplatin, Am. J. Pathol. 159 (2001) 1889-1894.

[25] D.M. Townsend, M.H. Hanigan, Inhibition of gamma-glutamyl transpeptidase or cysteine S-conjugate beta-lyase activity blocks the nephrotoxicity of cisplatin in mice, J. Pharmacol. Exp. Ther. 300 (2002) 142-148.

[26] A. Paolicchi, M. Sotiropuolou, P. Perego, S. Daubeuf, A. Visvikis, E. Lorenzini, et al., Gamma-glutamyl transpeptidase catalyses the extracellular detoxification of cisplatin in a human cell line derived from the proximal convoluted tubule of the kidney, Eur. J. Cancer 39 (2003) 996-1003.

[27] D.M. Townsend, M. Deng, L. Zhang, M.G. Lapus, M.H. Hanigan, Metabolism of Cisplatin to a nephrotoxin in proximal tubule cells, J. Am. Soc. Nephrol. 14 (2003) $1-10$.

[28] B.H. Ali, M. Al-Moundhri, M. Tageldin, I.S. Al Husseini, M.A. Mansour, A. Nemmar, et al., Ontogenic aspects of cisplatin-induced nephrotoxicity in rats, Food Chem. Toxicol. 46 (2008) 3355-3359.

[29] A.P. Favareto, C.D. Fernandez, D.A. da Silva, J.A. Anselmo-Franci, G. Kempinas Wde, Persistent impairment of testicular histology and sperm motility in adult rats treated with cisplatin at peri-puberty, Basic Clin. Pharm. Toxicol. 109 (2011) 85-96.

[30] P. Benedetto, Chemotherapy of testis cancer, Cancer Control 6 (1999) 549-559.

[31] K. Bachmann, D. Pardoe, D. White, Scaling basic toxicokinetic parameters from rat to man, Environ. Health Perspect. 104 (1996) 400-407.

[32] E.E. Brouwers, M.M. Tibben, H. Rosing, M.J. Hillebrand, M. Joerger, J.H. Schellens, et al., Sensitive inductively coupled plasma mass spectrometry assay for the determination of platinum originating from cisplatin, carboplatin, and oxaliplatin in human plasma ultrafiltrate, J. Mass Spectrom. 41 (2006) 1186-1194.

[33] R.H. Gallavan Jr., J.F. Holson, D.G. Stump, J.F. Knapp, V.L. Reynolds, Interpreting the toxicologic significance of alterations in anogenital distance: potential for confounding effects of progeny body weights, Reprod. Toxicol. 13 (1999) 383-390.

[34] R.T. Mitchell, W. Mungall, C. McKinnell, R.M. Sharpe, L. Cruickshanks, L. Milne, et al., Anogenital distance plasticity in adulthood: implications for its use as a biomarker of fetal androgen action, Endocrinology 156 (2015) 24-31.

[35] J.S. Kinsey-Jones, X.F. Li, A.M. Knox, Y.S. Lin, S.R. Milligan, S.L. Lightman, et al., Corticotrophin-releasing factor alters the timing of puberty in the female rat, J. Neuroendocrinol. 22 (2010) 102-109.

[36] M.T. Guerra, W.R. Scarano, F.C. de Toledo, J.A.A. Franci, G. Kempinas Wde, Reproductive development and function of female rats exposed to di-eta-butyl-phthalate (DBP) in utero and during lactation, Reprod. Toxicol. 29 (2010) 99-105.

[37] F.K. Marcondes, F.J. Bianchi, A.P. Tanno, Determination of the estrous cycle phases of rats: some helpful considerations, Braz. J. Biol 62 (2002) 609-614.

[38] C. Borgeest, D. Symonds, L.P. Mayer, P.B. Hoyer, J.A. Flaws, Methoxychlor may cause ovarian follicular atresia and proliferation of the ovarian epithelium in the mouse, Toxicol. Sci. 68 (2002) 473-478.

[39] C.E. Talsness, M. Shakibaei, S.N. Kuriyama, S.W. Grande, A. Sterner-Kock, P. Schnitker, et al., Ultrastructural changes observed in rat ovaries following in utero and lactational exposure to low doses of a polybrominated flame retardant, Toxicol. Lett. 157 (2005) 189-202.

[40] S. Panwar, M. Herrid, K.G. Kauter, J.R. McFarlane, Effect of passive immunization against leptin on ovarian follicular development in prepubertal mice, J. Reprod. Immunol. 96 (2012) 19-24.

[41] R. Mosquette, M.D. Simoes, I.D.C.G. da Silva, C.T.F. Oshima, R.M. Oliveira, M.A. Haidar, et al., The effects of soy extract on the uterus of castrated adult rats, Maturitas 56 (2007) 173-183.

[42] M. Mariani, P. Vigano, D. Gentilini, B. Camisa, E. Caporizzo, P. Di Lucia, et al., The selective vitamin D receptor agonist, elocalcitol, reduces endometriosis development in a mouse model by inhibiting peritoneal inflammation, Hum. Reprod. 27 (2012) 2010-2019.

[43] P. Petrusz, P. Dimeo, P. Ordronneau, C. Weaver, D.A. Keefer, Improved immunoglobulin-Enzyme bridge method for light microscopic demonstration of hormone-Containing cells of rat adenohypophysis, Histochemistry 46 (1975) 9-26.

[44] M.T. Guerra, M. Sanabria, G. Grossman, P. Petrusz, G. Kempinas Wde, Excess androgen during perinatal life alters steroid receptor expression, apoptosis, 
and cell proliferation in the uteri of the offspring, Reprod. Toxicol. 40 (2013) $1-7$.

[45] A.C. Nassr, A.C. Arena, F.C. Toledo, D.Z. Bissacot, C.D. Fernandez, A.L. Spinardi-Barbisan, et al., Effects of gestational and lactational fenvalerate exposure on immune and reproductive systems of male rats, J. Toxicol. Environ. Health A 73 (2010) 952-964.

[46] E. Reed, R.F. Ozols, R. Tarone, S.H. Yuspa, M.C. Poirier, The measurement of cisplatin DNA adduct levels in testicular cancer-patients, Carcinogenesis 9 (1988) 1909-1911.

[47] P.M. Petersen, S.W. Hansen, A. Giwercman, M. Rorth, N.E. Kakkebaek, Dose-Dependent impairment of testicular function in patients treated with cisplatin-Based chemotherapy for germ-cell cancer, Ann. Oncol. 5 (1994) 355-358.

[48] C.R. Nichols, S.D. Williams, P.J. Loehrer, F.A. Greco, E.D. Crawford, J. Weetlaufer, et al., Randomized study of cisplatin dose intensity in poor-risk germ-cell tumors-a southeastern-cancer-study-group and southwest-oncology-group protocol, J. Clin. Oncol. 9 (1991) 1163-1172.

[49] L.P. Rybak, D. Mukherjea, S. Jajoo, V. Ramkumar, Cisplatin ototoxicity and protection: clinical and experimental studies, Tohoku J. Exp. Med. 219 (2009) $177-186$.

[50] O. Ciftci, A. Cetin, M. Aydin, K. Kaya, F. Oguz, Fish oil, contained in eicosapentaenoic acid and docosahexaenoic acid, attenuates testicular and spermatological damage induced by cisplatin in rats, Andrologia 46 (2014) $1161-1168$.

[51] M. Leng, V. Brabec, DNA Adducts of Cisplatin, Transplatin and Platinum-intercalating Drugs, IARC scientific publications, 1994, pp. 339-348.

[52] A. Atessahin, I. Karahan, G. Turk, S. Gur, S. Yilmaz, A.O. Ceribasi, Protective role of lycopene on cisplatin-induced changes in sperm characteristics, testicular damage and oxidative stress in rats, Reprod. Toxicol. 21 (2006) 42-47.

[53] A.M. Bieber, L. Marcon, B.F. Hales, B. Robaire, Effects of chemotherapeutic agents for testicular cancer on the male rat reproductive system, spermatozoa, and fertility, J. Androl. 27 (2006) 189-200.

[54] H.F. Huang, L.M. Pogach, E. Nathan, W. Giglio, Acute and chronic effects of cisplatinum upon testicular function in the rat, J. Androl. 11 (1990) 436-445.

[55] J. Yeh, B. Kim, Y.J. Liang, J. Peresie, Mullerian inhibiting substance as a novel biomarker of cisplatin-induced ovarian damage, Biochem. Biophys. Res. Commun. 348 (2006) 337-344.

[56] L. Seethalakshmi, C. Flores, T. Kinkead, A.A. Carboni, R.K. Malhotra, M. Menon, Effects of subchronic treatment with cis-platinum on testicular function, fertility, pregnancy outcome, and progeny, J. Androl. 13 (1992) 65-74.
[57] T. Nakahara, Y. Uenoyama, A. Iwase, S. Oishi, S. Nakamura, S. Minabe, et al., Chronic peripheral administration of kappa-opioid receptor antagonist advances puberty onset associated with acceleration of pulsatile luteinizing hormone secretion in female rats, J. Reprod. Dev. 59 (2013) 479-484.

[58] J.M. Goldman, A.S. Murr, R.L. Cooper, The rodent estrous cycle: characterization of vaginal cytology and its utility in toxicological studies, Birth Defects Res. B Dev. Reprod. Toxicol. 80 (2007) 84-97.

[59] L. Detti, R.A. Uhlmann, M. Lu, M.P. Diamond, G.M. Saed, N.M. Fletcher, et al., Serum markers of ovarian reserve and ovarian histology in adult mice treated with cyclophosphamide in pre-pubertal age, J. Assist. Reprod. Genet. 30 (2013) 1421-1429.

[60] P. Kezele, E. Nilsson, M.K. Skinner, Cell-cell interactions in primordial follicle assembly and development, Front. Biosci. 7 (2002) d1990-6.

[61] M.E. Pepling, Follicular assembly: mechanisms of action, Reproduction 143 (2012) 139-149.

[62] I.D. Adler, A. el Tarras, Clastogenic effects of cis-diamminedichloroplatinum: II. Induction of chromosomal aberrations in primary spermatocytes and spermatogonial stem cells of mice, Mutat. Res. 243 (1990) 173-178.

[63] T.S. Barton, B. Robaire, B.F. Hales, Epigenetic programming in the preimplantation rat embryo is disrupted by chronic paternal cyclophosphamide exposure, Proc. Natl. Acad. Sci. U. S. A. 102 (2005) $7865-7870$.

[64] C.J. Marques, P. Costa, B. Vaz, F. Carvalho, S. Fernandes, A. Barros, et al., Abnormal methylation of imprinted genes in human sperm is associated with oligozoospermia, Mol. Hum. Reprod. 14 (2008) 67-74.

[65] H. Kobayashi, H. Hiura, R.M. John, A. Sato, E. Otsu, N. Kobayashi, et al., DNA methylation errors at imprinted loci after assisted conception originate in the parental sperm, Eur. J. Hum. Genet. 17 (2009) 1582-1591.

[66] R.G. Urdinguio, G.F. Bayon, M. Dmitrijeva, E.G. Torano, C. Bravo, M.F. Fraga, et al., Aberrant DNA methylation patterns of spermatozoa in men with unexplained infertility, Hum. Reprod. 30 (2015) 1014-1028.

[67] D. Chan, G. Delbes, M. Landry, B. Robaire, J.M. Trasler, Epigenetic alterations in sperm DNA associated with testicular cancer treatment, Toxicol. Sci. 125 (2012) 532-543.

[68] D.W. Shen, L.M. Pouliot, M.D. Hall, M.M. Gottesman, Cisplatin resistance: a cellular self-defense mechanism resulting from multiple epigenetic and genetic changes, Pharmacol. Rev. 64 (2012) 706-721.

[69] X. Chang, C.L. Monitto, S. Demokan, M.S. Kim, S.S. Chang, X. Zhong, et al., Identification of hypermethylated genes associated with cisplatin resistance in human cancers, Cancer Res. 70 (2010) 2870-2879. 